\title{
Bleeding Mandibular AVM: Airway Management
}

Editor, Arteriovenous Malformation (AVM) of mandible is a rare lesion that present with gingival bleeding, swelling and pain. These patients may present for the first time as life threatening haemorrhage. ${ }^{1,2}$ Securing the airway and giving general anaesthesia in such a patient with constant bleeding is a challenging task. We encountered this problem when an 8 year old female presented as a dental emergency with a profusely bleeding AVM of mandible. This patient presented with a 6 month history of intermittent bleeding from mouth which was misdiagnosed as haematemesis. A normal upper GI endoscopy and CT abdomen ruled out any GI pathology. Vascular surgeon's opinion was sought and on CT head and neck, AVM of mandible was diagnosed (Figure 1). A referral to oral surgery department was made for further management. Patient presented to emergency operation theatre as a dental emergency with continuous bleeding from the mandible. The bleeding was controlled by the surgeon by digital pressure, the release of which resulted in flooding of the airway with blood. Clinically the patient was anxious, restless, and pale with a heart rate of $130 / \mathrm{min}$ and blood pressure of $86 / 50 \mathrm{mmHg}$. Surgeons planned ligation of the external carotid artery with partial mandibulectomy. Intravenous access was secured with an $18 \mathrm{G}$ cannula. NIBP, $\mathrm{SPO}_{2}$, ECG were monitored. Preoxygenation was done with $100 \%$ $\mathrm{O}_{2}$ with anatomical face mask with continuous digital pressure by the surgeon on bleeding mandible. Fentanyl $30 \mu \mathrm{g}$ and thiopentone sodium $100 \mathrm{mg}$ was given intravenously. We were unable to maintain an adequate seal due to the finger present inside the mouth. Insertion of laryngeal mask airway (LMA) was also technically difficult and we failed to achieve its proper placement. Finally a Rendell-Baker mask was used to make a seal around the nose, with lips of the patient approximated with each other and around the oral pressure applying finger. (Figure2). Adequate seal was achieved and patient was easily ventilated. Succinylcholine $30 \mathrm{mg}$ i.v. was given and after 1 minute intubation was done with a cuffed endotracheal tube of $6.0 \mathrm{~mm}$ ID. Intraoperatively 1 unit of blood and 1 unit of FFP were transfused.
Surgery lasted for 3 hours. Rest of the perioperative course was uneventful and the patient was discharged after 7 days. RendellBaker mask has been designed for use in neonates and infants because of low dead space. In addition this has been used in edentulous elderly, over tracheostomy and in acromegaly. ${ }^{3,4}$ In our case a simple Rendell-Baker mask became the saviour when we were unable to achieve an adequate seal with an anatomical face mask and when a LMA could not be placed. With the advent of supraglottic airway devices, securing the airway has become quite easy for the anaesthetist and we are forgetting other techniques available. RendellBaker mask can be used for maintaining the airway in case of oral pathology or bleeding oral cavity where LMA or anatomical face mask cannot be used.
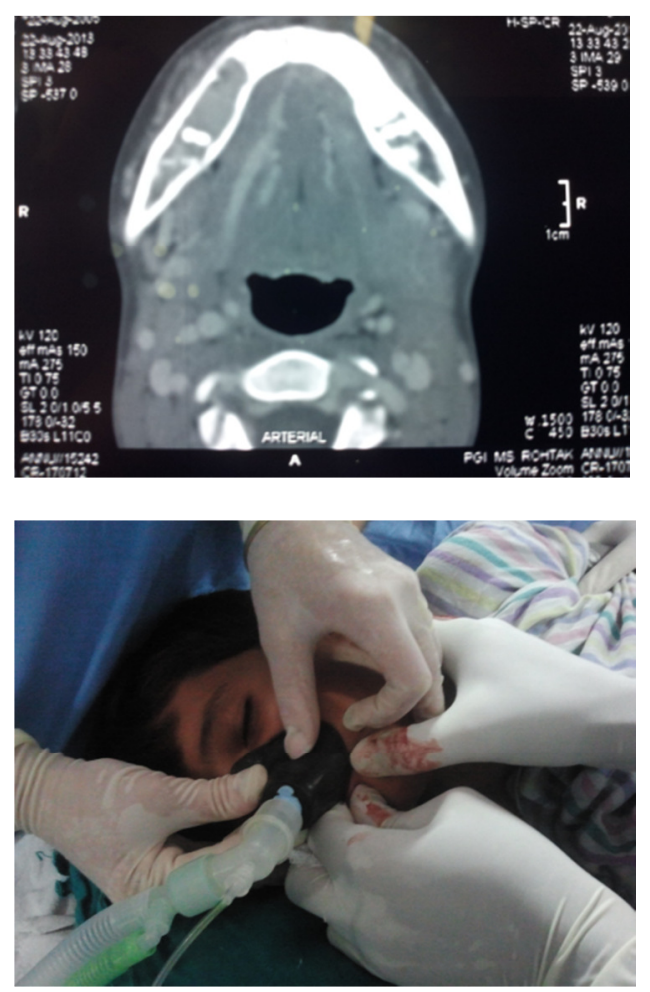

T Singh, S Saini, A Anand, J Lal, K Kaur Department of Anaesthesia, Pt. Bd Sharma, PGIMS, Rohtak, Haryana, India. 


\section{References}

1. Lamberg MA, Tasanen A, Jääskeläinen J. Fatality from central hemangioma of the mandible. J Oral Surg 1979; 37(8):578-84.

PMid: 312925

2. Anderson JH, Grisius RJ, McKeun TW. Arteriovenous malformation of the mandible. Oral Surg Oral Med Oral Pathol 1981; 52(2):118-25 http://dx.doi.org/10.1016/0030-4220(81)90306-6

3. Williamson R. Another use of pediatric masks. Anaesthesia 1992;47:361-2

http://dx.doi.org/10.1111/j.1365-2044.1992.tb02200.x PMid: 1482468

4. Kannan S, Birch JP. Controlled ventilation through tracheostomy stoma. Anesth Intens Care 2001;29:557 